\title{
COVID-19 và thế giới xuất bản học thuật
}

\author{
Hồ Mạnh Toàn \\ AI for Social Data Lab
}

Sự bùng phát của đại dịch COVID-19 kể từ đầu năm 2020 đến nay đã gây ra không ít xáo trộn cho các hoạt động xã hội, văn hóa và kinh tế. Đối với các nhà khoa học, quãng thời gian này yêu câu nỗ lực và sự lao động không ngừng nghỉ để có thể đưa ra các dự báo, kế hoạch phòng chống, và hướng giải quyết vấn đề này.

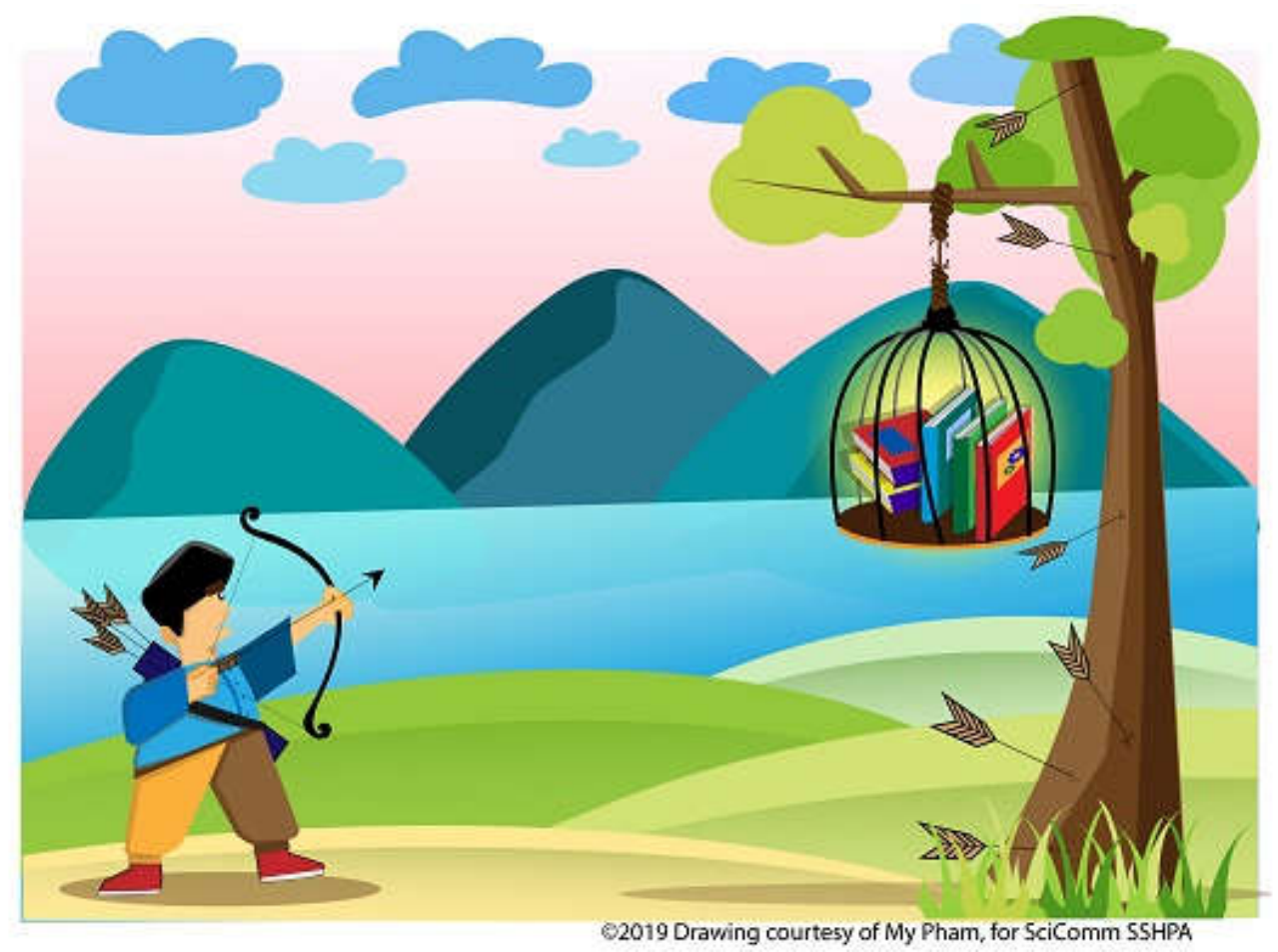

Để hỗ trợ các nhà khoa học, rất nhiều các nhà xuất bản, các tổ chức phi lợi nhuận, hay thư viện đã quyết định công bố mở hoàn toàn các nghiên cứu về virus SARS-CoV-2 và căn bệnh Covid-19. Danh sách nguồn tài nguyên này được LibraryLearningSpace tổng hợp, bao gồm các tên tuổi lớn như Elsevier, Springer Nature, PLOS, SAGE, The Lancet, JAMA Network, hay Cambridge University Press [1].

Bên cạnh tài nguyên khoa học, các khóa học trực tuyến hay các chương trình hỗ trợ học online cũng được IEEE, Coursera, Microsoft cung cấp miễn phí trong thời gian này [2].

Đây là hành động cần thiết của các nhà xuất bản học thuật để tạo ra điều kiện lý tưởng nhất, phục vụ cho việc phòng chống và phát triển vaccine cho COVID-19. Tuy nhiên, thực tế việc công bố mở các nghiên cứu khoa học hoàn toàn vốn đã được thúc đẩy mạnh, nổi bật là phong trào Plan S. Linda Lew của South China Morning Post 
nhận định đại dịch COVID-19 lần này vạch trần sự cũ kĩ và lỗi thời của mô hình kinh doanh của các nhà xuất bản học thuật hiện nay [3].

Mô hình xuất bản đóng hiện nay khiến các nghiên cứu, dù phần lớn được thực hiện bằng ngân sách công và được bình duyệt công ích, lại bị chặn truy cập và chỉ có thể đọc được với khoản phí khoảng 30 đô la cho một bài báo. Chính vì thế, việc một nhà xuất bản như Elsevier khóa chặt hơn 3800 nghiên cứu liên quan đến corona virus trong thời gian cấp bách này là khó có thể chấp nhận được. Chỉ với sức ép từ Tổ chức Y tế Thế giới thì Elsevier mới rục rịch để mở truy cập các nghiên cứu này.

Cũng cần phải nói rằng bản thân các biên tập viên và các nhà bình duyệt cũng đối mặt với nhiều khó khăn trong thời gian này [4]. Justin Weinberg của Daily Nous đã phỏng vấn một số biên tập viên của các tạp chí học thuật để có thể hiểu rõ hơn các vấn đề xảy ra trong thời gian dịch bệnh. Rõ rệt nhất là quá trình xét duyệt bản thảo chậm đi rất nhiều vì các nhà bình duyệt hay cả các biên tập viên đều đối mặt với nhiều trách nhiệm hơn: thiết lập hệ thống dạy học online, chăm sóc con cái vì trường nghỉ học. Trung bình trước đây, thời gian bình duyệt bản thảo có thể kéo dài từ $3-6$ tháng thì nay, nhiều nhà nghiên cứu hoàn toàn có thể đợi lâu hơn.

Mặc dù các nhà xuất bản đều tìm cách đẩy nhanh tốc độc xử lý bản thảo, đặc biệt là với các nghiên cứu COVID-19, thì yếu tố thời gian và khả năng truy cập vẩn khiến các nhà khoa học chủ động tìm đến các hệ thống preprints để có thể đưa các kết quả mới tới độc giả sớm nhất $[5,6]$. Trên medRxiv và bioRxiv, đã có 605 bản thảo về COVID-19 được đăng tải, đóng góp nhiều thông tin quan trọng cho thế giới. Trong những ngày vừa qua, một số tác giả Việt Nam cũng đã đóng góp các kết quả, quan sát mới về thời gian phát hiện virus ở bệnh nhân [7] hay sự bền vững của hệ thống y tế công cộng Việt Nam giữa đại dịch COVID-19 [8] trên các hệ thống preprint.

\section{medR $\chi$ iv}

THE PREPRINT SERVER FOR HEALTH SCIENCES

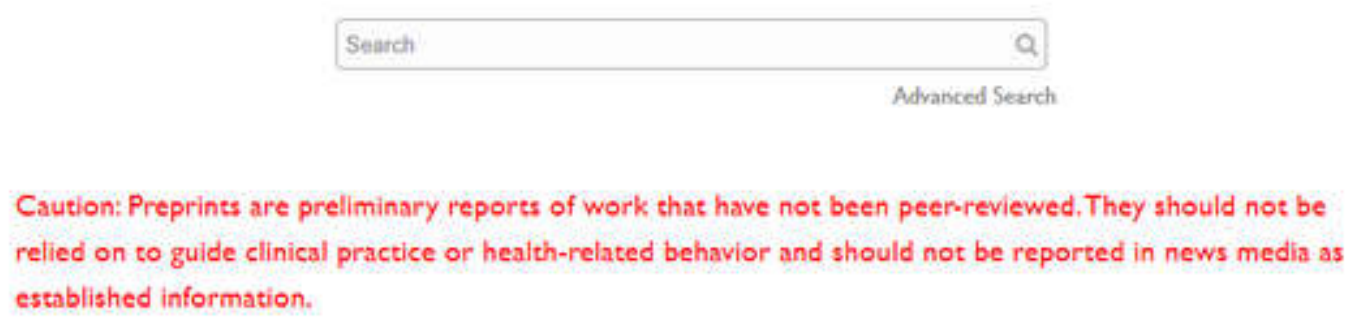

COVID-19 SARS-CoV-2 preprints from medRxiv and bioRxiv

Tuy nhiên, vấn đề của các hệ thống này là thiếu khâu bình duyệt khắt khe của các tạp chí thông thường. Vì vậy, có thể các kết quả sai, gây tranh cãi cũng được đăng tải và gây ra nhiễu loạn thông tin. Ví dụ, một bản thảo cho thấy sự giống nhau giữa virus SARS-CoV-2 và virus HIV đã gây tranh cãi lớn, gây ra các thuyết âm mưu, và 
nhanh chóng được bioRxiv rút khỏi hệ thống. Hai tác giả Ivan Oransky và Adam Marcus đã lên tiếng cảnh báo về sự cần thiết của cơ chế kiểm tra, rút bài, đặc biệt là ở các hệ thống preprint [9].

Mặc dù vậy, sự tranh cãi cũng không chừa cả các nghiên cứu đã xuất bản. Ví dụ như nghiên cứu Bat Coronaviruses in China công bố năm 2019 bất ngờ bùng nổ lượng đọc và theo dõi trên tạp chí Viruses [10]. Cái tên hút khách cũng như một tác giả làm việc tại cơ sở nghiên cứu ở Vũ Hán đã khiến bài viết đã được sử dụng rất nhiều trong các thuyết âm mưu. Tính đến nay, bài viết đã có gần 78000 lượt xem tóm tắt, và tải về tới hơn 106000 lần, đứng đầu các nghiên cứu được xem nhiều nhất của tạp chí.

Đối mặt với những trắc trở giữa mùa dịch, các tiếng nói tiên phong đến từ Nature hay Science trở thành kim chỉ nam quan trọng cho cộng đồng khoa học. Ngày 16-03 vừa qua, tác giả Shibo Jiang kêu gọi chỉ sử dụng vaccine chống COVID-19 khi đã đảm bảo an toàn trên Nature [11]. Cùng ngày, tổng biên tập tạp chí Science, H. Holden Thorp, kêu gọi trách nhiệm và lòng trắc ẩn từ mỗi cá nhân để chúng ta có thể vượt qua bài kiểm tra thiên niên kỉ này: sự hỗ trợ cần thiết từ cơ quan nghiên cứu, đồng nghiệp, để đảm bảo các bộ phận chăm sóc lâm sàng, nghiên cứu virus, hay truyền thông sức khỏe cộng đồng có thể an tâm làm việc [12].

Note: Published on EASE Vietnam SciComm System (URL: https://sc.sshpa.com/post/5643), and ISR Phenikaa University (URL: http://isr.phenikaa-uni.edu.vn/chitiet/su-kien 2019222759 334/covid-19-vathe-gioi-xuat-ban-hoc-thuat).

\section{References:}

[1] LibraryLearningSpace. (2020). Free resources for 2019 Novel Coronavirus (COVID19). Library Learning Space. Retrieved from https://librarylearningspace.com/free-resources-2019-novel-coronavirus2019-ncov/

[2] LibraryLearningSpace. (2020). Free educational resources provided to learners affected by coronavirus outbreak. Library Learning Space. Retrieved from https://librarylearningspace.com/free-resources-provided-learners-affectedcoronavirus-outbreak/

[3] Lew, L. (2020). Will the coronavirus kill off the 'dinosaur' world of academic publishing?. South China Morning Post. Retrieved from https://www.scmp.com/news/china/article/3075431/will-coronavirus-killdinosaur-world-academic-publishing

[4] Weinberg, J. (2020). Academic Journals During the Pandemic. DailyNous. Retrieved from http://dailynous.com/2020/03/17/academic-journalspandemic/ 
[5] MedRxiv. (2020). COVID-19 SARS-CoV-2 preprints from medRxiv and bioRxiv. medRxiv. Retrieved from https://connect.medrxiv.org/relate/content/181

[6] Vuong, Q. H. (2019). Breaking barriers in publishing demands a proactive attitude. Nature Human Behaviour, 3(10), 1034. doi: 10.1038/s41562-019-0667-6. https://www.nature.com/articles/s41562-019-0667-6.

[7] Ngoc, N. M., That, B. T. T., Hong, N. T. T., Dung, N. T. P., Thanh, T. T., Man, D. N. H., ... \& Chau, N. V. V. (2020). Duration of viral detection in throat and rectum of a patient with COVID-19. medRxiv. DOI: https://doi.org/10.1101/2020.03.07.20032052

[8] La, V., Pham, T., Ho, T. M., Hoang, N. M., Linh, N. P. K., Vuong, T., ... Vuong, Q. (2020). Policy response, social media and science journalism for the sustainability of the public health system amid COVID-19 outbreak: The Vietnam lessons. SocArXiv. DOI: https://doi.org/10.31235/osf.io/cfw8x

[9] Fan Y, Zhao K, Shi Z.-L., Zhou P. (2019). Bat Coronaviruses in China. Viruses, 11(3), 210. http://dx.doi.org/10.3390/v11030210

[10] Oransky, I., Marcus, A. (2020). Quick retraction of a faulty coronavirus paper was a good moment for science. STAT. Retrieved from https://www.statnews.com/2020/02/03/retraction-faulty-coronavirus-papergood-moment-for-science/

[11] Jiang, S. (2020). Don't rush to deploy COVID-19 vaccines and drugs without sufficient safety guarantees. Nature, 579, 321, doi: 10.1038/d41586-02000751-9.

[12] Thorp, H. H. (2020). Time to pull together. Science, eabb7518, DOI:10.1126/science.abb7518 